Simone G. Assis 1

Joviana Q. Avanci 1

Cosme M. F. P. Silva 2

Juaci V. Malaquias 1

Nilton C. Santos 1

Raquel V. C. Oliveira 1

\section{A representação social do ser adolescente: um passo decisivo na promoção da saúde}

The social representation to be adolescent: a decisive step to health promotion
1 Escola Nacional de Saúde Pública e Centro LatinoAmericano de Estudos de Violência e Saúde Jorge Careli (Claves), da Fiocruz. Av. Brasil 4036/700

Manguinhos, 21040-261 Rio de Janeiro RJ.

simone@claves.fiocruz.br

2 Instituto Brasileiro de Geografia e Estatística.
Abstract This article approaches the adolescence in an original perspective: the feeling that the adolescent possesses on himself, the values and competence. It is a survey that investigates the self-concept and self esteem of 1.686 adolescents studying in private and public schools in a municipal district of Rio de Janeiro, São Gonçalo. It aims to know the social representation that adolescents do about themselves. As approach methodological the technique used is "theory of the central nucleus". The results indicate that the adolescents have the positive vision of themselves, conjugating the idea of happiness/good mood and satisfaction with the body, in spite of the vision that the adults and the society in general have of them. The optimist self vision of the adolescents need to be recognized and implemented in the strategies of promotion of the health, prevention and attention to the health.

Key words Adolescence, Self-esteem, Health promotion
Resumo Este artigo aborda a adolescência de forma original: o sentimento que o adolescente possui sobre si mesmo, seus valores e competência. Apresenta os resultados de um inquérito epidemiológico que investiga o autoconceito e a auto-estima de 1.686 adolescentes escolares das escolas públicas e particulares de São Gonçalo, município do Estado do Rio de Janeiro. Objetiva conhecer a representação social que esses adolescentes fazem de si próprios. Utiliza-se a técnica denominada "teoria do núcleo central" como arcabouço metodológico. Os resultados indicam que os adolescentes têm uma visão muito positiva de si próprios, conjugando a idéia de alegria/bom humor/extroversão e satisfação com o corpo, a despeito da visão que os adultos e a sociedade em geral têm deles. A partir disso, conclui-se que a otimista visão de si do adolescente precisa ser reconhecida e implementada nas estratégias de promoção da saúde, prevenção e atenção dos agravos à saúde.

Palavras-chave Adolescência, Auto-estima, Promoção da saúde 
Em quase todos os países do mundo, vem crescendo nas últimas décadas o estudo sobre a adolescência, fase apontada por Françoise Dolto como bem menos conhecida que a infância. Embora ainda pouco estudada, tem sido vista desde a Antiguidade pelo prisma da impulsividade e excitabilidade. Aristóteles (300 a.C.) os considerava "apaixonados, irascíveis e inclinados a se deixarem levar por seus impulsos" (Kiell, apud Newcombe, 1999). Platão advertia quanto ao uso de bebida alcoólica antes dos 18 pois "não se pode colocar fogo no fogo" (Platão, apud Newcombe, 1999).

A adolescência é um período de mudança e transição, que afeta os aspectos físicos, sexuais, cognitivos e emocionais. Aberastury e Knobel (1992) a concebem como a fase da reorganização emocional, de turbulência e instabilidade, caracterizada pelo processo biopsíquico a que os adolescentes estão destinados. A corrente de identificação da adolescência como uma fase de "tempestade e estresse" (Hall, apud Newcombe, 1999) e dos adolescentes como "conflituosos e conturbados" (Tommasi, 1999) ainda perdura na sociedade, embora hoje se perceba que esta concepção foi "grandemente exagerada" (Bee, 1996).

Com a intenção de aprofundar e enriquecer o debate sobre a temática dessa fase da vida, que pode ser analisada sob diferentes ângulos, este artigo aborda a adolescência de forma original: o sentimento que o adolescente possui sobre si mesmo, seus valores e competência. Investiga, portanto, o autoconceito e a auto-estima de adolescentes escolares das escolas públicas e particulares de um município do Estado do Rio de Janeiro, São Gonçalo. Busca, em última instância, conhecer a representação social que esses adolescentes fazem de si próprios. Essas representações estão tanto na "cultura quanto na cognição" (Farr, 1994), circulando na comunicação social cotidiana e diferenciado-se segundo os grupos sociais (Sá, 1996).

As representações sociais configuram um assíduo objeto de pesquisa das ciências sociais, recebendo distintas contribuições de diferentes correntes do pensamento, tais como Durkheim (1978), Weber (1974), Shutz (1979) e Marx (1984). Podem ser definidas como senso comum, imagens, concepções e visão de mundo que os atores sociais possuem sobre a realidade (Minayo, 1999). As representações sociais dos indivíduos se compõem de figuras e expressões socializadas, frutos da vivência das contradições que permeiam o dia-a-dia dos indiví- duos dos diferentes estratos sociais; também são resultados do conteúdo psíquico, da individualidade de cada um, que interpreta as figuras e expressões socializadas segundo seu próprio potencial. São, ao mesmo tempo, "ilusórias, contraditórias e verdadeiras” e consideradas matéria-prima para a análise do social e também para a ação pedagógica-política de transformação. Retratam a realidade, embora não a conformem, não se podendo tomá-la como verdade científica, nem reduzi-la à concepção que os atores sociais fazem dela (Minayo, 1999).

As representações sociais que os indivíduos fazem de si próprios compõem um tema de interesse mais freqüente da psicologia social. O autoconceito pode ser considerado uma organização hierárquica e multidimensional de um conjunto de percepções de si mesmo. O conteúdo dessas percepções é tudo aquilo que o indivíduo reconhece como fazendo parte de si. É adaptável, regulado pelo dinamismo individual, pelas características da interação social e pelo contexto situacional. É eminentemente social, já que gera e é gerado nas interações sociais (Tamayo, 1981). Reflete uma visão mais racional de si próprio.

A auto-estima é uma parte do autoconceito. Expressa um sentimento ou uma atitude de aprovação ou de repulsa de si mesmo, e até que ponto o sujeito se considera capaz, significativo, bem-sucedido e valioso. É o juízo pessoal de valor expresso nas atitudes que o indivíduo tem consigo mesmo. É uma experiência subjetiva acessível às pessoas através de relatos verbais e comportamentos observáveis (Coopersmith, 1967; Rosenberg, 1989).

Costa (2000) enfatiza que a auto-estima é talvez a variável mais crítica que afeta a participação exitosa de um adolescente com outros em um projeto. Os adolescentes com baixa auto-estima desenvolvem mecanismos que provavelmente distorcem a comunicação de seus pensamentos e sentimentos e dificultam a integração grupal.

Tanto o autoconceito quanto a auto-estima são a base da representação social que o adolescente tem de si mesmo. São atributos profundamente individuais, embora moldados nas relações cotidianas desde a primeira infância. São também fatores decisivos na relação do indivíduo consigo mesmo e com os outros, exercendo uma marcante influência na percepção dos acontecimentos e das pessoas, influenciando de forma considerável o comportamento e as vivências do indivíduo (Sánchez \& Escribano, 1999; 1969). 
Mruk (1995) sugere pelo menos cinco razões fundamentais para a necessidade de um enfoque científico na consideração da auto-estima: 1) é um fenômeno muito mais complexo do que parece, pois está fortemente associado a outros construtos da personalidade; 2) está implicada na vida cotidiana, já que se relaciona à saúde mental ou bem-estar psicológico; 3) pode ser um valor depreciativo de si mesmo, que se relaciona com graves fenômenos mentais como depressão, suicídio, sentimentos de inadequação e ansiedade; 4) a auto-estima parece ter se tornado um conceito indispensável às ciências sociais, uma vez que aborda a percepção das pessoas sobre si mesmas, tendo uma interlocução direta com a experiência das condições sociais básicas, estruturais e relacionais vividas na sociedade; 5) esta temática nunca alcançou o significado social como o obtido no momento atual.

Desta forma, a auto-estima e o autoconceito, bases da representação que o indivíduo tem de si, se colocam no campo da saúde pública, uma vez que envolvem o bem-estar individual e social. Mecca et al. (1989) enfatizam que a saúde da sociedade depende em grande parte do estado psicológico com que as pessoas se colocam frente a um desafio. Paralelamente a isso, o National Advisory Health Council (1996) considera a auto-estima o principal indicador de saúde mental. Embora seja reconhecida, internacionalmente, a valiosa importância da percepção de si mesmo nas relações sociais, no Brasil há uma ausência de estudos enfocando o autoconceito e a auto-estima, especialmente a do adolescente, havendo um desconhecimento da magnitude que a visão de si mesmo possui na vida pessoal e social.

\section{Metodologia}

Este artigo é parte de uma pesquisa denominada "Auto-estima, autoconceito e violência. Um estudo socioepidemiológico em escolares de São Gonçalo", desenvolvida no ano de 2002 (Assis e Avanci, 2003). Apenas os aspectos referentes aos temas abordados no artigo estão apresentados a seguir.

\section{Definição da amostra e tamanho amostral}

A população de referência foi composta por adolescentes estudantes das escolas públicas (municipais e estaduais) e particulares do mu- nicípio de São Gonçalo (RJ), no ano de 2002. Esse município integra a Região Metropolitana do Estado do Rio de Janeiro, sendo o segundo maior município do Estado em termos populacionais e o décimo quinto do país, com uma população de 889.828 habitantes vivendo em área urbanizada. Trinta e cinco por cento da população está na faixa de 0 a 19 anos de idade (IBGE, 2001).

A amostra foi dimensionada para se obterem estimativas de proporção, com precisão de $5 \%$, nível de confiança de $95 \%$ e a maior variabilidade possível $-\mathrm{p}=50 \%$ (Cochran, 1965). O plano amostral definiu quatro estratos segundo as séries escolares (7ạ/8a séries do ensino fundamental e 1으o ano do ensino médio) das unidades públicas e privadas do município. $\mathrm{Pa}$ ra cada um dos estratos, adotou-se um esquema de amostragem aleatória estratificada de unidades conglomeradas com um único estágio de seleção. As turmas foram selecionadas com amostragem aleatória simples dentro de cada estrato.

O banco analisado no presente trabalho foi consolidado com 1.685 alunos, sendo 938 meninas e 747 meninos, embora no município de São Gonçalo exista proporção similar de jovens segundo o sexo na faixa etária dos 10 aos 19 anos (IBGE/Censo Demográfico - Contagem Populacional, 2002). Há ainda uma leve predominância de jovens $(50,3 \%)$ na faixa etária dos 11 aos 14 anos. Foram visitadas 44 turmas, constituindo 38 escolas do município, num universo de 177 escolas públicas e 151 particulares.

\section{Dados sociodemográficos}

Apresenta-se a distribuição da representação social segundo sexo e faixa etária (10-14 anos e 15-19 anos). Também foram aferidas informações que determinavam o estrato social dos jovens investigados. Utilizou-se o critério de classificação econômica adotado pela Associação Brasileira de Institutos de Pesquisa de Mercado (Abipeme), avaliado pelo poder de compra da família, segundo uma lista de bens domésticos e pessoais, e da escolaridade do chefe da família (quando presente, o pai; e quando ausente, a mãe). Na amostra de escolares de São Gonçalo, 55\% pertencem aos estratos sociais mais elevados (A e B) e os restantes aos estratos populares (C, D e E). 


\section{Escala de auto-estima}

A escala de auto-estima de Rosenberg é um instrumento criado em 1965, amplamente utilizado e conhecido internacionalmente (Rosenberg, 1989). É uma medida unidimensional com 10 itens designados a avaliar globalmente a atitude positiva ou negativa de si mesmo. São eles: se os jovens se sentem satisfeitos consigo mesmos; se têm várias boas qualidades; se às vezes sentem que não prestam para nada; se não têm muito do que se orgulhar de si próprios; se sentem que são um fracasso; se percebem que são inúteis; se desejariam ser uma pessoa de valor, ter mais respeito por si e ter uma atitude positiva em relação a si próprio; se são capazes de fazer coisas tão bem quanto os outros. As opções de resposta são: concordo totalmente, concordo, discordo, discordo totalmente. Uma elevada auto-estima é indicada por um escore alto.

Em um estudo realizado por Ho et al. (1995) o coeficiente alfa de Cronbach para as meninas e os meninos foi de 0.82 e 0.74 , respectivamente. Nunes (apud Hutz, 2002) indica que a escala de Rosenberg segue sendo o instrumento mais utilizado em pesquisa, em função de suas boas propriedades psicométricas e a sua fácil aplicabilidade.

Na presente pesquisa foi realizada a adaptação transcultural dessa escala de acordo com o modelo de equivalência proposto por Herdman (1998). Foi efetuada revisão bibliográfica na população original e na alvo; traduções e retraduções independentes do inglês para o português e vice-versa; consulta com expert lingüístico; discussão com experts da área de interesse que avaliaram as etapas anteriores e definiram os itens que comporiam a escala; e avaliação psicométrica e pré-testagem na população-alvo.

A adaptação do instrumento foi considerada eficiente. Na etapa de tradução e retradução do instrumento, em comparação com o original, os avaliadores consideraram inalterada a maior parte dos itens, em seu sentido geral; e receberam índices superiores a $80 \%$, no sentido referencial. No pré-teste verificou-se um alfa de Cronbach de 0.68 , a correlação intraclasse (ICC) de 0.70 e kappa predominantemente moderado. Na análise fatorial três fatores foram gerados, com grau de explicação de 54\% da variância. Quanto à validade convergente, a escala de auto-estima correlacionou-se, dentre outras questões, com a escala de violência psi- cológica e apoio social, que teoricamente convergem com este construto.

Os escores obtidos tiveram como pontos de corte os tercis, consolidando três gradientes de intensidade: auto-estima elevada, moderada e baixa. No presente trabalho apresentam-se apenas os pólos extremos da auto-estima, referentes aos 32,3\% que evidenciaram visão muito positiva quanto ao próprio valor e competência e os $40,7 \%$ que registraram percepções muito negativas do próprio valor e competência. Embora o grupo de baixa auto-estima seja maior que o de elevada auto-estima, tal fato se deve ao recurso metodológico dos tercis utilizado para essa avaliação. Para se aferir com maior fidedignidade a prevalência dos diferentes níveis de auto-estima seria necessário um estudo comparativo dos distintos pontos de corte, tema ainda em debate na bibliografia internacional.

\section{A teoria do núcleo central da representação social}

O estudo das representações sociais tem larga expressão em investigações qualitativas, possuindo diversas abordagens metodológicas. Avalia a forma como o indivíduo se conduz no ambiente social, material e ideativo, orientando a conduta, a comunicação social e estabelecendo uma realidade sociocultural comum (Minayo et al., 1999). Neste artigo utiliza-se uma técnica denominada Teoria do Núcleo Central oriunda da psicologia social, para aferir a representação social. Essa teoria utiliza um instrumental estatístico para análise dos dados, embora a abordagem subjacente a ela seja de natureza essencialmente qualitativa (Moscovici, 1984; Sá 1996; Jodelet, 2001; Abric, 2001).

Abric (2001) toma como hipótese geral para seu estudo experimental das representações sociais que toda representação se organiza em torno de um núcleo central (elemento fundamental da representação), que, por ser estruturante da representação, tem função geradora (cria ou transforma a significação dos outros elementos da representação) e organizadora (determina a natureza dos vínculos que unem entre si os demais elementos da representação). O núcleo central é um subconjunto da representação cuja ausência desestruturaria ou daria uma significação radicalmente diferente à representação em seu conjunto. Por outro lado, é o elemento mais estável da representação, o que mais resiste à mudança. Uma representação é suscetível de evoluir e de se transformar 
superficialmente por uma mudança no sentido ou da natureza de seus elementos periféricos. Mas ele só muda de significação quando o próprio núcleo central é posto em questão.

Existem diversas estratégias de aferição para o núcleo central. No presente estudo foi incluído um item no questionário quantitativo, em que cada entrevistado, por meio da técnica da associação livre, era solicitado a falar cinco palavras que lhe viessem à mente sobre a maneira como se vê e se sente, refletindo o autoconceito que tem de si. As palavras proferidas pelos entrevistados foram, posteriormente, categorizadas segundo a freqüência média e a ordem média de evocação em que são ditas, compondo quatro quadrantes de análise: um núcleo central e três periféricos (Abric, 1994; Sá, 1996).

Durante a análise dos dados, deu-se procedimento à categorização dos termos coletados em torno de eixos temáticos que expressassem o mesmo sentido, conteúdo e carga emocional. Foram coletadas 612 palavras diferentes (cerca de 8.000 evocações no total, incluindo as repetições), que compuseram 28 eixos temáticos.

Os eixos mais freqüentes e que foram citados nos primeiros lugares das falas ocuparam o núcleo central. Esse núcleo constitui para os adolescentes o conceito essencial e prioritário, estabelecido a partir da informação que receberam, de sua introjeção e interpretação. É composto pelas palavras proferidas em primeiro ou segundo lugar dentre as cinco, e com freqüência acima da média. O núcleo periférico 1 é formado por eixos temáticos muito freqüentes (acima da freqüência média), mas pouco priorizados nos primeiros lugares de evocação; o núcleo periférico 2 compõe-se de palavras que, embora tenham sido citadas menos vezes (abaixo da freqüência média), o foram nos primeiros lugares; e no núcleo periférico 3 estão os eixos de menor importância, pois congregam aqueles menos evocados e comentados nos últimos lugares da fala. Nos resultados apresentados foram excluídas as categorias que representaram menos de $1 \%$ do total de evocações.

As principais categorias e as palavras que surgiram mais freqüentemente estão listadas a seguir.

1) Imagem corporal: percepções diretas e indiretas que o sujeito tem do seu corpo, e a maneira como este é percebido pelos outros.

- Características de satisfação com o corpo: alto, atraente, bonito, elegante, gostoso, lindo, magro, vaidoso.
- Características de insatisfação com o corpo: baixo, feio, gordo.

2) Atitudes emocionais no contato com o próximo: percepções das atitudes reativas emocionais e afetivas disponibilizadas pelo indivíduo nos seus relacionamentos interpessoais e com a sociedade em geral.

- Atitudes de amizade, ajuda, atenção, carinho, compreensão e cuidado com as pessoas: amável, amigo, atencioso, carinhoso, companheiro, compreensivo, cuidadoso, gentil, solidário.

- Atitudes anti-sociais, de antipatia e distanciamento com as pessoas: chato, metido, orgulhoso.

3) Experiência emocional de aceitação: percepções das experiências emocionais do indivíduo resultantes da sua procura por interação, complementaridade, e necessidade de reconhecimento pelos outros. Palavras mais mencionadas: amado, bem-aceito, correspondido, elogiado, protegido, querido.

4) Estados emocionais: diz respeito à maneira como percebe o próprio humor.

- Estados emocionais de alegria, ânimo, bom humor e bem-estar: alegre, animado, bem, contente, feliz, legal, maneiro, otimista.

- Estados emocionais de tristeza, ansiedade e mau humor: ansioso, triste, mal-humorado.

5) Atributos comportamentais voltados para o estudo, o trabalho e ocupações: percepções da maneira como o indivíduo disciplina suas atividades, sua performance, e suas habilidades cognitivas ligadas ao aprendizado.

- Atributos que expressam competência, habilidade e facilidade no aprendizado: atento, ativo, corajoso, criativo, curioso, dedicado, determinado, educado, esforçado, esperto, estudioso, inteligente, interessado, organizado, persistente, pontual, realista, realizado, responsável, seguro, trabalhador.

- Atributos que expressam incompetência, inabilidade e dificuldade no aprendizado: burro, desligado, desorganizado, distraído, ignorante, indeciso, preguiçoso.

6) Atributos de sociabilidade: percepções da predisposição social do indivíduo, das suas inclinações concernentes ao relacionamento interpessoal, da sua abertura aos outros e da sua capacidade pessoal de comunicação. Palavras mais citadas: brincalhão, comunicativo, divertido, engraçado, extrovertido, simpático, sorridente.

7) Atributos de comportamento: percepção da sua maneira de agir ou reagir, indicando assim seu grau de equilíbrio, agressividade e impulsividade. 
- Atributos que refletem tranqüilidade, calma e equilíbrio: calmo, meigo, paciente, pacífico, quieto, tranqüilo.

- Atributos que refletem inquietude, agressividade e impulsividade: agitado, bravo, brigão, genioso, impaciente, nervoso, rebelde, vingativo.

8) Atributos afetivos nas relações: percepções das emoções e sentimentos existentes nas relações em geral. Menções mais comuns: amoroso, apaixonado, ciumento, romântico, sensível, sentimental, sonhador.

9) Atitudes e valores ético-político-morais positivos e valorizados socialmente: imagem da dignidade moral do indivíduo. Auto-avaliações e percepções sociais provenientes dos outros e interiorizadas pelo sujeito. Falas mais freqüentes: bondoso, fiel, franco, generoso, honesto, humilde, justo, leal, obediente, sincero, verdadeiro. 10) Grau de satisfação pessoal: diz respeito às impressões de valorização pessoal positivas ou negativas que o indivíduo tem de si próprio.

- Impressões de valorização pessoal: bom, forte, interessante, maravilhoso, ótimo, satisfeito.

- Impressões de satisfação mediana consigo próprio: diferente, normal, simples.

\section{Questões éticas}

Para a execução da pesquisa, foi obtida autorização da Secretaria Municipal de Educação de São Gonçalo e da Coordenadoria da Metro- politana II, órgão representante da Secretaria Estadual de Educação em São Gonçalo. A direção das escolas públicas e particulares e os alunos assinaram Consentimentos Livres e Esclarecidos, conforme preconizado na Resolução 196/ 96 do Conselho Nacional de Saúde, que normatiza as pesquisas com seres humanos. A pesquisa também foi aprovada pelo Comitê de Ética em Pesquisa da Escola Nacional de Saúde Pública/Fiocruz.

\section{Resultados}

Os alunos das redes pública e particular mostraram uma visão muito positiva de si próprios quando solicitados a escreverem cinco palavras que descrevessem como se vêem e se sentem. Conjugam atributos que combinam idéias de exuberância, excitação, beleza, inteligência e amizade. Em suas próprias palavras, os adolescentes se vêem "irados". Somando todos os atributos positivos apresentados no quadro 1 , alcança-se $77,1 \%$ das evocações. Apenas 18,1\% têm conotação negativa.

Essa visão positiva pode ser constatada nas principais categorias que representam a forma como os adolescentes se percebem. A primeira delas é a alegria/bom humor/extroversão, ambas presentes no núcleo central, representando 23,5\% do total das evocações (Quadro 1). Foram faladas com freqüência superior a 288,4 e

Quadro 1

Representação social dos adolescentes sobre si próprios. São Gonçalo/RJ, 2002

Ordem média $=3,1$ evocações, Frequência média $=288$ evocações

\begin{tabular}{|c|c|}
\hline $\begin{array}{l}\text { Núcleo Central - NC } \\
\text { - estados emocionais de alegria e bom humor }(14,7 \%) \\
\text { - } \text { atributos que expressam extroversão }(8,8 \%) \\
\text { - } \text { satisfação com o corpo }(8,2 \%)\end{array}$ & $\begin{array}{l}\text { Núcleo Periférico } 1 \\
\text { - atitudes de amizade e cuidado com pessoas }(14,3 \%) \\
\text { - atitudes que expressam competência }(11,7 \%) \\
\text { - valores ético-político-morais positivos }(9,9 \%)\end{array}$ \\
\hline $\begin{array}{l}\text { Núcleo Periférico } 2 \\
\text { - } \text { atributos que refletem tranqüilidade/equilíbrio }(3,6 \%) \\
\text { - } \text { atributos que expressam introversão }(3 \%) \\
\text { - } \text { satisfação mediana consigo próprio }(2,9 \%) \\
\text { - impressões de valorização pessoal }(2,4 \%) \\
\text { - insatisfação com o corpo }(2,3 \%) \\
\text { - } \text { estados emocionais de tristeza e mau humor }(2,2 \%)\end{array}$ & $\begin{array}{l}\text { Núcleo Periférico } 3 \\
\text { - atributos afetivos nas relações }(3,5 \%) \\
\text { - atitudes anti-sociais/distanciamento pessoas }(2,8 \%) \\
\text { - } \text { atributos refletindo inquietude/impulsividade }(2,8 \%) \\
\text { - } \text { atributos que expressam incompetência }(2,1 \%)\end{array}$ \\
\hline
\end{tabular}

Nota: 2,3\% abstenção; no respondentes $=1.673$; no evocações $=8.076 ; 4,8$ palavras por sujeito. 
ordenadas na fala em primeiro ou segundo lugar. As principais definições mencionadas foram: legal, feliz, alegre, simpático, brincalhão, divertido, engraçado e extrovertido. Esses atributos refletem um autoconceito positivo, em que características emocionais como o humor e a capacidade pessoal de comunicação são fundamentais. Esses atributos são inerentes a uma fase da vida em que a esperança e o otimismo são muito valorizados, além de serem próprios de uma imagem de juventude socialmente construída na mídia e na sociedade em geral.

Outra representação compõe o núcleo central ( $8,2 \%$ do total de evocações): a satisfação com o corpo. Reflete a imagem corporal que tem de si, intimamente dependente da valorização sociocultural e histórica existente na sociedade. Evidencia mais o corpo experienciado pelo adolescente do que o corpo objetivo (anatomia/fisiologia). A palavra de maior destaque neste grupo é bonito, indicando o quanto a beleza corporal está presente como valor para a juventude.

No núcleo periférico 1 (NP1) encontra-se uma outra importante categoria da representação social dos adolescentes sobre si - as atitudes de amizade, ajuda, atenção, carinho, compreensão e cuidado com as pessoas (14,3\% do total de evocações). Esta categoria esteve muito freqüentemente na fala de todos os adolescentes, embora tenha sido lembrada posteriormente as categorias antes descritas. É outro importante conceito para se compreender a representação que os adolescentes têm de si. As palavras mais mencionadas foram: amigo e carinhoso, demonstrando o elevado valor afetivo presente na fala dos adolescentes e nas relações que estabelece.

Também no núcleo periférico 1 estão os atributos relacionados à competência pessoal ( $11,7 \%$ do total de evocações). As palavras mais mencionadas foram: inteligente e responsável.

Os valores ético-morais positivos completam o núcleo periférico 1 (9,9\% do total de evocações). Esse autoconceito está baseado nos valores que $\mathrm{o}$ adolescente julga serem bons. Os termos mais mencionados foram: sincero, fiel, humilde e honesto.

Embora todas as categorias do NP1 sejam proporcionalmente mais faladas que as categorias relativas às pertencentes ao núcleo central, ocuparam posição secundária, foram lembradas posteriormente, significando que o adolescente ordena a representação que tem de si próprio colocando em destaque os atributos de alegria/extroversão e satisfação corporal, seguidos pelos de amizade, competência e valores éticos-morais.

Os demais núcleos têm menor destaque, pelo fato de poucos alunos mencionarem as categorias que os compõem. No caso do NP2, ele se compõe por palavras que foram ditas logo no início da fala, contendo duas categorias positivas e quatro negativas:

- atitudes que demonstram calma, tranqüilidade e equilíbrio $(3,6 \%)$ : a palavra mais evocada foi calmo.

- valorização pessoal $(2,4 \%)$ : bom e forte foram as mais proferidas;

- introversão (3\%): tímido se destacou por ser muito mencionada;

- satisfação mediana de si (2,9\%): simples foi a palavra mais informada;

- insatisfação com o corpo (2,3\%): ser gordo, feio e baixo são os atributos mais referidos;

- estados emocionais de tristeza e mau humor $(2,2 \%)$ : a palavra triste se destaca dentre todas.

No NP3 estão as menos faladas e mais tardiamente lembradas. Está composto por uma categoria positiva e três negativas:

- atributos afetivos nas relações $(3,5 \%)$ : amoroso, romântico e sensível foram as palavras mais mencionadas;

- atitudes anti-sociais/distanciamento pessoas $(2,8 \%)$ : metido e chato se destacaram;

- atributos refletindo inquietude/impulsividade $(2,8 \%)$ : nervoso e impaciente foram as evocações mais comuns;

- atributos que expressam incompetência $(2,1 \%)$ : burro, desligado, desorganizado, distraído, ignorante, indeciso, preguiçoso.

No quadro 2 pode-se observar a representação social dos adolescentes segundo algumas variáveis: sexo, faixa etária, estrato social e auto-estima.

Em relação ao estrato social, nota-se que os jovens de melhor condição socioeconômica se distinguem dos estratos mais empobrecidos economicamente, falando mais categorias positivas $(\mathrm{p}=0,000)$. Entretanto, essa diferença é tênue. Comparando a estrutura do núcleo central dos jovens de mais elevado estrato com os de mais baixo nível socioeconômico, tem-se: a inclusão das palavras que significam amizade e cuidado com as pessoas (distinguindo-se também do padrão geral no quadro 1); mais palavras que expressam extroversão e satisfação com o corpo; discreta redução de evocações que lembram estados de alegria e bom humor. No NP1, nota-se que há a inclusão de mais duas 
Quadro 2

Representação social de escolares de São Gonçalo (RJ), segundo sexo, faixa etária, estrato social e auto-estima e número de evocações

\begin{tabular}{|c|c|c|c|c|c|c|c|c|}
\hline & \multicolumn{2}{|c|}{ Estrato social $\left({ }^{\star}\right)$} & \multicolumn{2}{|c|}{ Faixa etária } & \multicolumn{2}{|c|}{$\operatorname{Sexo}\left(^{*}\right)$} & \multicolumn{2}{|c|}{ Auto-estima $\left(^{\star}\right)$} \\
\hline & $\begin{array}{c}A+B \\
N=3194\end{array}$ & $\begin{array}{l}\mathrm{C}+\mathrm{D}+\mathrm{E} \\
\mathrm{N}=2610\end{array}$ & $\begin{array}{c}10-14 \\
\mathrm{~N}=4000\end{array}$ & $\begin{array}{c}15-19 \\
N=3937\end{array}$ & $\begin{array}{c}\text { Masc. } \\
\mathrm{N}=3483\end{array}$ & $\begin{array}{c}\text { Fem. } \\
\mathrm{N}=4593\end{array}$ & $\begin{array}{l}\text { Elevada } \\
\mathrm{N}=2492\end{array}$ & $\begin{array}{c}\text { Baixa } \\
\mathrm{N}=3041\end{array}$ \\
\hline \multicolumn{9}{|l|}{ Núcleo central } \\
\hline $\begin{array}{l}\text { Estados emocionais } \\
\text { de alegria e bom humor }\end{array}$ & 14,8 & 15,2 & 15 & 14,4 & 14,2 & 15,2 & 14,9 & 14,9 \\
\hline Satisfação com o corpo & 8,5 & 7,3 & 8,8 & 7,6 & 10,4 & 6,5 & 8,4 & 7,5 \\
\hline $\begin{array}{l}\text { Atitudes de amizade } \\
\text { e cuidado com as pessoas }\end{array}$ & 14,2 & - & - & - & - & 16,1 & - & 13,8 \\
\hline $\begin{array}{l}\text { Valores ético-político- } \\
\text { morais positivos }\end{array}$ & - & 9,8 & - & - & - & - & - & - \\
\hline $\begin{array}{l}\text { Atributos que expressam } \\
\text { extroversão }\end{array}$ & 10,1 & 7,7 & 9,1 & 8,6 & - & 9,3 & - & - \\
\hline $\begin{array}{l}\text { Atributos que refletem } \\
\text { tranqüilidade e equilíbrio }\end{array}$ & - & - & - & 3,7 & 4,2 & - & - & 4,1 \\
\hline \multicolumn{9}{|l|}{ Núcleo periférico 1} \\
\hline $\begin{array}{l}\text { Atitudes de amizade } \\
\text { e cuidado com as pessoas }\end{array}$ & - & 14,8 & 13,7 & 14,8 & 12 & - & 15,8 & - \\
\hline $\begin{array}{l}\text { Atitudes que expressam } \\
\text { competência }\end{array}$ & 12 & 12,2 & 11,9 & 11,8 & 12,3 & 11,3 & 13,8 & 9,2 \\
\hline $\begin{array}{l}\text { Valores ético-político- } \\
\text { morais positivos }\end{array}$ & 10,1 & - & 9,4 & 10,4 & 9,7 & 10 & 10,1 & 9,1 \\
\hline $\begin{array}{l}\text { Atributos que expressam } \\
\text { extroversão }\end{array}$ & - & - & - & - & 8,3 & - & 10 & 8,5 \\
\hline $\begin{array}{l}\text { Atributos afetivos } \\
\text { nas relações }\end{array}$ & 3,7 & - & - & - & - & 4,3 & - & - \\
\hline $\begin{array}{l}\text { Atributos que refletem } \\
\text { tranqüilidade e equilíbrio }\end{array}$ & 3,7 & - & - & - & - & - & - & - \\
\hline \multicolumn{9}{|l|}{ Núcleo periférico 2} \\
\hline $\begin{array}{l}\text { Atributos que expressam } \\
\text { introversão }\end{array}$ & 2,2 & 3,7 & 2,8 & 3,2 & 3 & 3 & 2,6 & 3,4 \\
\hline $\begin{array}{l}\text { Impressões de satisfação } \\
\text { mediana consigo próprio }\end{array}$ & 2,5 & 3,1 & 2,7 & 3,1 & 3,3 & 2,6 & 2,6 & 3,2 \\
\hline $\begin{array}{l}\text { Impressões de } \\
\text { valorização pessoal }\end{array}$ & 1,9 & - & 2,3 & - & 3,6 & 1,6 & 2,5 & - \\
\hline Insatisfação com o corpo & 2,4 & 1,8 & 2,7 & 1,9 & 2,5 & 2,1 & 1,4 & 3,5 \\
\hline Atributos afetivos nas relações & - & - & - & - & - & - & - & 3,5 \\
\hline $\begin{array}{l}\text { Atributos que refletem } \\
\text { tranqüilidade e equilíbrio }\end{array}$ & - & 3,7 & - & - & - & - & - & - \\
\hline $\begin{array}{l}\text { Estados emocionais } \\
\text { de tristeza e mau humor }\end{array}$ & 1,7 & 2,5 & - & 2,6 & - & 2,6 & - & 3,2 \\
\hline
\end{tabular}

continua 
Quadro 2

continuação

\begin{tabular}{cccccccc}
\multicolumn{2}{c}{ Estrato social $\left({ }^{*}\right)$} & \multicolumn{2}{c}{ Faixa etária } & \multicolumn{2}{c}{ Sexo $\left(^{*}\right)$} & \multicolumn{2}{c}{ Auto-estima $\left(^{*}\right)$} \\
$\mathrm{A}+\mathrm{B}$ & $\mathrm{C}+\mathrm{D}+\mathrm{E}$ & $10-14$ & $15-19$ & Masc. & Fem. & Elevada & Baixa \\
$\mathrm{N}=3194$ & $\mathrm{~N}=2610$ & $\mathrm{~N}=4000$ & $\mathrm{~N}=3937$ & $\mathrm{~N}=3483$ & $\mathrm{~N}=4593$ & $\mathrm{~N}=2492$ & $\mathrm{~N}=3041$ \\
\hline
\end{tabular}

Núcleo periférico 3

Impressões de valorização pessoal

Atributos afetivos

nas relações

Atributos que refletem

tranqüilidade e equilíbrio

Atitudes anti-sociais/

distanciamento das pessoas

Atributos que refletem

inquietude e impulsividade

Estados emocionais

de tristeza e mau humor

Atributos que expressam

incompetência

$\begin{array}{llllllll}- & 2,4 & - & 2,5 & - & - & - & 1,9 \\ - & 3,5 & 3,4 & 3,5 & 2,5 & - & 3,7 & - \\ - & - & 3,5 & - & - & 3,1 & 3,5 & - \\ 2,4 & 3 & 2,9 & 2,7 & 1,9 & 3,5 & 1,9 & 3,3 \\ 3 & 2,8 & 2,9 & 2,7 & 2,2 & 3,2 & 1,8 & 3,4 \\ - & - & 1,8 & - & 1,7 & - & 1,4 & - \\ 2,3 & 1,9 & 2,5 & 1,7 & 2,8 & 1,6 & 1,4 & 2,9\end{array}$

$\left.{ }^{*}\right) \mathrm{p}=0,000$

№ respondentes: estrato social $(\mathrm{AB}=669 ; \mathrm{CDE}=538)$; faixa etária $(10-14=833 ; 15-19=824)$;

sexo $($ masc. $=747$; fem. $=938)$; auto-estima $($ alta $=511$; baixa $=644)$

categorias, também consideradas positivas: atributos afetivos nas relações e que refletem tranqüilidade e equilíbrio.

Não se encontrou diferença estatisticamente significativa nas palavras evocadas entre as faixas etárias estudadas, seguindo de perto o padrão observado no quadro 1. Já em relação ao sexo, encontram-se diferenças significativas $(\mathrm{p}=0,000)$. As moças evidenciam no núcleo central mais atributos de estados de alegria, bom humor e extroversão que os rapazes (mais também do que os apresentados no quadro 1); evocam bem menos palavras que refletem a satisfação com o corpo; e introduzem como central em suas representações as evocações que referem amizade e cuidado com as pessoas. Os rapazes posicionam no núcleo central as expressões de tranqüilidade e equilíbrio, enquanto as moças as ordenaram nos últimos lugares e com freqüência mais baixa. Há ainda um percentual um pouco maior de rapazes que se definem pela competência pessoal.

Em relação à auto-estima, também se notou distinção significativa $(\mathrm{p}=0,000)$. As categorias positivas foram proporcionalmente mais mencionadas pelos respondentes com mais ele- vada auto-estima (a maioria situada no NC e NP1). Já os jovens de mais baixa auto-estima trazem para o núcleo central a idéia de calma e tranqüilidade, além de se destacarem pelas falas de todas as categorias consideradas negativas (situadas nos NP2 e NP3) em comparação aos com melhor percepção de si mesmos. A interferência da auto-estima sobre o adolescente pode ser bem visualizada pelo percentual dos que se dizem competentes: $13,8 \%$ e $9,2 \%$, respectivamente alta e baixa auto-estima (NP2).

\section{Discussão dos resultados}

A opção por trabalhar com a teoria do núcleo central das representações sociais foi uma dentre as muitas possibilidades existentes para se entender a representação social. Para melhor aprofundá-la uma nova fase poderia ser realiza$\mathrm{da}$, visando confrontar e checar quais as representações têm capacidade geradora das demais representações e organizadora das relações entre as demais. Para tanto, seria necessária uma nova incursão no campo. Embora tal confrontação não tenha sido feita, a conjunção dos re- 
sultados apresentados neste artigo com a compreensão da representação social efetuada através de entrevistas com os jovens na mesma pesquisa (Assis e Avanci, 2003) fortalece os achados aqui apresentados e a pertinência de se adotar a teoria do núcleo central da representação social ao se trabalhar com grandes amostras.

O mais importante resultado deste trabalho é o reconhecimento de que os adolescentes possuem uma visão muito positiva de si próprios, a despeito da visão que os adultos e a sociedade em geral têm deles. Os adolescentes de São Gonçalo revelam a visão positiva de si próprios, definida especialmente pela alegria, bom humor, extroversão e satisfação corporal, características de uma fase de desenvolvimento pontuada por mudanças emocionais e físicas, conflitos e transformações. Trata-se de uma visão que enfatiza os atributos positivos em detrimento de qualidades negativas.

Essas representações mostraram-se também presentes nas entrevistas individuais que foram realizadas com alguns jovens (Assis e Avanci, 2003). Através da análise de conteúdo percebeu-se que os valores mais fortemente introjetados pelos adolescentes foram: alegria, otimismo, extroversão, capacidade de "brincar com a vida", "prazer em fazer os outros rirem"; estética: a valorização do físico; respeito aos outros; igualdade entre as pessoas; amizade com franqueza e sinceridade; solidariedade: ajudar pessoas da família e necessitadas.

Atributos que refletem impulsividade e agressividade foram pouco mencionados nas abordagens metodológicas utilizadas. Tal fato merece destaque para as estratégias de promoção da saúde e prevenção de situações de risco. Reconhecer o aspecto alegre e de bom humor do adolescente minimiza a distância do adulto com essa fase da vida, o que possibilita uma convivência mais sadia e, para o adolescente, uma base segura para a estruturação de sua identidade.

Vale ressaltar que adolescentes com baixa auto-estima possuem uma visão menos satisfatória que os de mais elevada auto-estima. Contudo, essa percepção sobre si mesmos ainda é positiva. Nas entrevistas individuais realizadas constataram-se inúmeras contradições quanto ao próprio valor e competência diante da insegurança e fragilidade desses adolescentes com menor satisfação consigo mesmo.

É certo que adolescência é um período que merece atenção e cuidado, principalmente dos pais, educadores e profissionais de saúde; entretanto reconhecer essa fase da vida sob um prisma sombrio e obscuro pode limitar práticas potencializadoras.

A otimista visão de si do adolescente precisa ser reconhecida e implementada nas estratégias de promoção da saúde, prevenção e atenção dos agravos à saúde. A mudança do paradigma vem sendo apontada por autores que trabalham com jovens: atividades relacionadas aos comportamentos de risco devem derivar e serem resultado de um intenso trabalho sobre a auto-estima e construção da identidade do adolescente (Costa, 2000; Serrão e Baleeiro, 1999). Este enfoque tem de priorizar os atributos individuais, a influência da família, o meio social, o espírito de época, que se juntam numa síntese pessoal, configurando em cada ser humano um microcosmo sui generis (Claves, 2000).

Cabe relembrar que uma representação de si tão positiva não significa a "realidade" tal como ela é percebida pela sociedade, nela incluindo a mídia como um mecanismo de socialização. Mas, sim, representações sociais de jovens que, situados em diferentes esferas da vida cotidiana, teceram palavras muito positivas, sobrepujando "uma multidão de fios ideológicos” (Bakthin, apud, Minayo, 1999), freqüentemente negativos a seu respeito.

Uma pesquisa domiciliar realizada por $\mathrm{Mi}$ nayo et al. (1999), com jovens do município do Rio de Janeiro, mostrou uma visão igualmente positiva. Utilizando a mesma metodologia do presente trabalho, tinha como objetivo conhecer as representações sociais sobre a juventude. Encontrou que jovens do Rio de Janeiro associam alegria, beleza e bondade; diversão e lazer; direitos e deveres; e namoros à concepção de juventude. Também incluem no núcleo central duas idéias negativas: álcool/drogas e violência/criminalidade. Ressalta-se que esses jovens estão falando sobre o conceito de juventude em geral, e não exclusivamente da representação de si próprio.

Minayo et al. (1999) comentam que a imagem extremamente positiva que os jovens têm de si mesmos talvez funcione como uma defesa perante a sociedade, que transparece uma visão negativa sobre juventude. Essa visão positiva, segundo os autores, não traduz ingenuidade, pois a uma visão global do "ser jovem" se conjuga uma reflexão do porquê ser da forma que se é, apesar dos conflitos na aceitação da forma de ser e sentir e ambigüidades naquilo que se deseja ser.

Em relação às diferenças na representação social de si encontradas nos grupos sociais, há 
dificuldade em se afirmar categoricamente a questão. Estudos têm mostrado resultados ambíguos (Ho et al., 1995; Rosenberg, 1989). Mruk (1995) afirma que não é o estrato social que define a auto-estima, mas o fato de a criança encontrar referências positivas no seu próprio grupo cultural. Pode-se dar como exemplo uma criança muito pobre que se valoriza muito, pois, no seu grupo de referências encontrou alguém que lhe inculque apreço e valor pelo que se é.

No que tange aos resultados similares encontrados nas faixas etárias estudadas, pouco se conhece sobre oscilações da visão de si do adolescente. Marsh (1989), investigando sobre o autoconceito, observa que este tende a declinar da pré-adolescência até a metade dessa fase de desenvolvimento, quando então começa a aumentar. Reiterando esse pensamento, Bee (1996) destaca que os primeiros anos da adolescência se caracterizam por mais negativismo que os anos mais tardios.

As diferenças observadas em relação ao sexo são mais relatadas na bibliografia. Mruk (1995) destaca que o maior cuidado dispensado culturalmente às meninas pode torná-las mais vulneráveis e menos confiantes em si. Nessa linha de pensamento, o autor indica que meninas valorizam mais temas como a aceitação e rejeição de si mesmas, enquanto os homens tendem a avaliar a si próprios a partir da dimensão de competência (sucesso e fracasso). Segundo ele, essas diferenças podem ser resultantes da biologia ou da criação (cultura e aprendizado). Entretanto, evidências sugerem que essas diferenças de gênero nascem como conseqüência dos distintos modelos de interação social e experiências interpessoais que caracterizam homens e mulheres desde os primeiros anos de vida (Belenky et al., 1986).

Smith \& Muenchen (1995) lembram que há inconsistências e controvérsias sobre a questão de gênero e auto-estima. Enquanto alguns pes- quisadores encontram auto-estima mais elevada nos meninos (Martinez \& Dukes apud Smith \& Muenchen, 1995), outros concluem que as meninas se sobrepõem aos meninos (Ribeiro, 1988), e ainda outros não encontram diferenças entre eles (Isberg et al. apud Smith \& Muenchen, 1995). Rosenberg (1989) noticia uma possível interação entre gênero e auto-estima, mas não afirma com consistência essa relação.

As diferentes percepções de si segundo o nível de auto-estima possuem respaldo na literatura. Adolescentes de elevada auto-estima tendem a um "afeto positivo", acreditam na sua competência e no seu valor (Coopersmith, 1967; Rosenberg, 1989). Demonstram capacidade para lidar com desafios, são auto-eficientes e conseguem se adaptar mais facilmente a uma situação. Essas pessoas são mais independentes, autônomas e percebem a realidade mais acuradamente. Já os adolescentes com baixa auto-estima são mais sensíveis a críticas dirigidas a eles. Sofrem de um "afeto negativo", com sentimentos de inferioridade, menos valia, isolamento e insegurança. Têm um grande senso de proteção consigo. A vulnerabilidade é uma característica marcante (Assis e Avanci, 2003).

Por fim, vale retomar a concepção de adolescência e juventude como potencial de transformação da sociedade, pelas condutas desafiadoras, pela inconformidade com a ordem vigente e pelas manifestações culturais que propicia. Chaves Júnior (1999), considera que a juventude se distingue das outras gerações não pela faixa etária, mas pelo conteúdo que simboliza, sendo responsável por determinar, de forma mais veemente, o ritmo da história. Resta a nós, profissionais encarregados de promover a saúde dos adolescentes, aprender a utilizar a visão positiva de si que eles possuem, tendo como meta subsidiá-los na aceitação de seus potenciais e limites e na capacidade de "ousar" a vida, pois apenas assim se alcança a aceitação do outro e a transformação da sociedade.

\section{Agradecimentos}

A pesquisa recebeu suporte do Conselho Nacional de Desenvolvimento Científico e Tecnológico/CNPq. Também contou com bolsistas da Fundação de Amparo à Pesquisa do Rio de Janeiro - Faperj, e do Programa PIBIC do $\mathrm{CNPq}$ /Fiocruz. 


\section{Referências bibliográficas}

Aberastury A \& Knobel M 1982. Adolescência normal. Editora Artes Médicas, Porto Alegre.

Abric JC 2001. O estudo experimental das representações sociais. In D Jodelet (org.). As representações sociais. Editora EdUERJ, Rio de Janeiro.

Abric JC 1994. Pratiques sociales et représentation. PUF, Paris.

Assis S \& Avanci J 2003. O auto-conceito, a auto-estima e a violência. Estudo socioepidemiológico em escolares de São Gonçalo (RJ). Relatório final de pesquisa. Claves, Rio de Janeiro.

Bee H 1996. A criança em desenvolvimento. Editora Artes Médicas, Porto Alegre.

Belenky MF, Clinchy BM, Goldberger NR \& Tarule JM 1986. Women's ways of knowing: the development of self, voice and mind. Basic Books, Nova York.

Branden N 1969. The psychology of self-esteem. Bantam, Nova York.

Chaves Júnior EO 1999. Políticas de juventude: evolução histórica e definição, pp. 41-48. In Cadernos Juventude, Saúde e Desenvolvimento. Ministério da Saúde, Brasília.

Claves (Centro Latino-Americano de Violência e Saúde Jorge Careli) 2000. Avaliação do processo de implantação e dos resultados do Programa Cuidar. Relatório final de pesquisa. Claves, Rio de Janeiro.

Coopersmith S 1967. The antecedents of self-esteem. Freeman, São Francisco.

Costa ACG 2000. Protagonismo juvenil: adolescência, educação e participação democrática. Fundação Odebrecht, Salvador.

Durkheim E 1978. As regras do método sociológico, pp. 71-156. Pensadores. Editora Abril, São Paulo.

Farr R 1994. Representações sociais: a teoria e sua história, pp. 155-172. In P Guareschi \& S Jovchelovitch (org.). Textos em representação social. Editora Vozes, Petrópolis.

Fiocruz/ENSP/Claves 2000. Avaliação do processo de implantação e dos resultados do "Programa Cuidar": 1a fase. Relatório final de pesquisa. Claves, Rio de Janeiro.

Herdman M, Fox-Rushby J \& Badia X 1998. A model of equivalence in the cultural adaptation of HRQol instruments: the universalist approach. Quality of Life Research 4:323-335.

Ho CS, Lempers JD \& Clark-Lempers DS 1995. Effects of economic hardship on adolescent self-esteem: a family mediation model. Adolescence 30(117):117-131.

Hutz CS 2002. Situações de risco e vulnerabilidade na infância e na adolescência: aspectos teóricos e estratégias de interação. Casa do Psicólogo, São Paulo.

IBGE (Instituto Brasileiro de Geografia e Estatística) 2001. Síntese de indicadores sociais 2000. Fundação Instituto Brasileiro de Geografia e Estatística, Rio de Janeiro.
IBGE (Instituto Brasileiro de Geografia e Estatística) 2002. Censo demográfico - Contagem Populacional 2002.

Jodelet D 2001. As representações sociais: um domínio em expansão, pp. 17-44. In D Jodelet (org.). As representações sociais. Editora EdUERJ, Rio de Janeiro.

Marsh HW 1989. Age and sex effects in multiple dimensions of self-concept preadolescence to Early adulthood. Journal of Educational Psychology 81(3):417430 .

Marx K \& Engels F 1984. A ideologia alemã. Hucitec, São Paulo.

Mecca A, Smelser NJ \& Vasconcellos J 1989. The social importance of self-esteem. University of California Press, Berkeley.

Minayo MCS et al. 1999. Fala galera. Juventude, violência e cidadania na cidade do Rio de Janeiro. Garamond, Rio de Janeiro.

Minayo MCS 1999. O desafio do conhecimento. Pesquisa qualitativa em saúde. Hucitec-Abrasco, São PauloRio de Janeiro.

Moscovici S 1984. The phenomenon of social representations, pp. 3-69. In RM Farr \& S Moscovici (eds.). Social representations. University Press, Cambridge.

Mruk C 1995. Self-esteem: research, theory, and practice. Springer Publishing Company, Nova York.

National Advisory Mental Health Council 1996. Basic behavioral science research mental health: vulnerability and resilience. American Psychologist 51:22-28.

Newcombe N 1999. Desenvolvimento infantil. Abordagem de Mussen. Artmed, São Paulo.

Ribeiro MA 1988. O autoconceito de adolescentes segundo o sexo e a estrutura familiar. Psicologia: Teoria $e$ Pesquisa 4(2):85-95.

Rosenberg M 1989. Society and the adolescent self-image. Princeton University Press, Princeton

Sá CP 1996. Núcleo central das representações sociais. Vozes, Petrópolis.

Sánchez AV \& Escribano EA 1999. Medição do autoconceito. Edusc, Bauru.

Serrão M \& Baleeiro MC 1999. Aprendendo a ser e a conviver. FTD, São Paulo.

Shutz A 1979. Fenomenologia e relações sociais. Zahar, Rio de Janeiro.

Smith DE \& Muenchen RA 1995. Gender and age variations in the self-image of Jamaican adolescents. Adolescence 30:119.

Tamayo A 1981. EFA: Escala Fatorial de Autoconceito. Arquivos Brasileiros de Psicologia 33(4):87-102.

Tommasi MCF 1999. Desenvolvimento emocional e cognitivo do adolescente, pp. 33-48. In FB Assumpção, Kuczynski (eds.). Adolescência normal e patológica. Lemos Editorial, São Paulo.

Weber M 1974. A objetividade do conhecimento nas ciências e na política social. Editora Lisboa Ltda., Lisboa 